\title{
Keynotes
}

\section{London capitation weighting: social deprivation, homelessness and mental health}

\author{
StuART TuRner, Consultant Psychiatrist and Medical Director; and \\ CAROLYN HASKINS, Research Psychologist, Camden \& Islington Community Health \\ Services NHS Trust, 112 Hampstead Road, London NW1 2LT
}

Inner London, together with many other inner city areas, faces a crisis of funding in health services. Budgets are now allocated to commissioning authorities primarily on the basis of the sizes of resident populations. Although it is recognised that different communities have different needs and that some adjustment to this simple approach (capitation weighting) is required, there is no clarity about the best mechanism to achieve a fair resolution (Stern, 1992). Those inner city areas with high levels of social deprivation, high indices of health service need and especially those with high numbers of homeless people require additional resources to provide acceptable levels of overall care. Failure to take adequate account of these pressures may result in further gradual reductions in funding and consequently in service provision.

The current allocation of resources to regional health authorities by a weighted capitation formula dependent on the Standard Mortality Ratio (SMR) as a proxy for health need has already been criticised by Sir Bernard Tomlinson (1992). The London context, in which older and infirm people often move elsewhere to die, dictates that inner London districts gain insufficient benefit from this death statistic. The review of capitation formulae proposed by Tomlinson, and in particular the recognition of the inaccuracy of the SMR methodology, the proposed inclusion of morbidity data, improved recognition of the needs of homeless people and acknowledgment of the high costs in inner London, stands to provide an important means for starting to achieve appropriate means of applying resources to communities based on need.

The present paper will examine the impact of extreme social deprivation, commonly experienced by homeless people, on mental health services and the implications for a revised weighted capitation formula.

Mental health services are particularly vulnerable to the added needs arising from social deprivation for three reasons. (a) Social deprivation in the resident population. There are particularly large differences in need for mental health services according to level of social deprivation. This factor affects acute psychiatric demand within single provider services as well as between providers and is therefore unlikely to be a consequence simply of differing patterns of service provision (Royal College of Psychiatrists, 1988). In a total population study of all psychiatric admissions in England using 1986 Mental Health Enquiry data $(168,652$ admissions after exclusion of mental handicap and psychogeriatrics), Jarman et al (1992) further developed this analysis and described a statistical model using social deprivation which explains much of the difference between districts in admission rates $(r=0.84)$. This simple model compared well with the best available regression analysis using a much more complex dataset; the complex model achieved only a marginally higher correlation $(r=0.89)$. However, because both these models provide only indirect predictions of the number of beds required, they have not been validated against the actual numbers of beds needed in those districts which have a high number of admissions of homeless people. Similarly, a social deprivation index and unemployment level were demonstrated to be two of the most important determinants of accumulation of new long-stay patients (Thornicroft et al, 1992) in inner London; social deprivation accounted for $55 \%$ of the variation between districts and unemployment for $81 \%$ of the variation.

(b) Very high psychiatric morbidity in the homeless groups. The homeless include a high proportion of people with major mental illness. Although it is hard to obtain a reliable figure, it is possible that about a third have schizophrenia and that this is a major contributing factor in their becoming homeless (Timms \& Fry, 1989; James, 1991). Neither is homelessness adequately accounted for in measures of social deprivation. One of the most widely used measures of social deprivation is the Jarman index; based on 1981 census data, this measure inevitably 
relies more heavily on resident rather than homeless populations. Similar criticism applies to other indices such as the new scale under consideration for use in North East Thames (Stern, 1992).

(c) Social services pressures. Where the community is deprived, there are likely to be additional pressures on local authority services, with knock-on effects on health service provisions (e.g. in discharge planning). These difficulties probably result from a combination of declining budgets in these areas and increasing service pressures on social as well as health service resources. In a recent survey in Bloomsbury \& Islington, the single most important reason for the retention in hospital care of people who were felt to be clinically ready for discharge was failure to provide appropriate move-on accommodation (Pilling \& Fox, personal communication). The impact of new care in the community procedures is still under review.

\section{Homelessness and a weighted capitation formula}

In a recent article in the Health Services Journal, a new formula for weighted capitation was proposed based on the Access to Health project (Stern, 1992). This attempted to link differences in admission rate between homeless and locally resident people to a method of calculating equivalent population bases. Thus for each of four categories of homelessness (temporary accommodation, squats, hostels and sleeping out) a weighting factor was proposed which would permit the translation of estimated numbers of homeless people into the equivalent number of residents who would make the same scale of demand on services. For example, it was estimated that there were 165 people sleeping out in the Riverside health authority area. Using an estimated admission rate (all acute specialties) for this homeless group of 4.7 times that of the resident population, this was taken to indicate that these 165 people were equivalent to $(165 \times 4.7)$, i.e. 776 , residents in terms of generic acute hospital service demand. By adding the revised figure to the resident population count, a more accurate estimate of equivalent population could be determined. It was suggested that this was a more appropriate figure to use in capitation calculations.

The principle is laudable and produces a simple mechanism for these calculations. However, it will be argued that it is insufficient to account for the added burden facing these inner city authorities for three reasons.

(a) The weighting. The project has produced weightings for each of the four classes of homelessness and proposes that these are of general applicability. They are based on limited data from parts of inner London (Scheuer et al, 1991) and in one case from a survey restricted to West Lambeth, since identified as having unusual characteristics (Jarman et al, 1992). Implicit in these proposals is the assumption that these weightings will have wider validity and can be used in conjunction with valid district-bydistrict estimates of numbers of homeless people within each of these categories. This is unlikely to be the case and takes no account of the differential effects of other social pressures on inner-city districts on the one hand or the patchy availability of voluntary sector provision on the other.

(b) The quality of the data. This applies to hospital data as well as to results of community surveys. Existing hospital information systems generally underestimate numbers of homeless people. For example, those in bed \& breakfast (B \& B) and private sector leased (PSL) addresses are often not detected. The recent survey reported by Scheuer $e t$ al (1991) was explicit about some of these problems of identification in relation to squatters, some homeless people in hostels and those with "care of" addresses.

Similarly, surveys of homeless people, especially the roofless, are always incomplete and therefore significantly underestimate the scale of the need. The survey method requires some means of fixing a reference point for sample collection. It works reasonably well for resident populations where a complete list of addresses can be obtained and a complete or sample survey can be made. For homeless people, surveys will miss people who are moving at the time of data collection, people who are not visible to the survey team, and people who do not meet the stereotyped expectations of the surveyors. These problems are especially obvious in the roofless homeless. The number obtained, therefore, will always be a significant underestimate. Of more importance, the degree of under-estimation is impossible to calculate and will vary from place to place and time to time. It is relatively easy to see the construction of new homes, affecting the resident population; it is relatively hard to detect transient flows in the homeless community. New epidemiological techniques, based on methods used to identify the size and characteristics of mobile populations in ethological research, are under evaluation (Fisher $e t$ al, in preparation) but until a valid methodology can be agreed, any system based on extrapolations from survey data will be of limited value. It is a very poor basis on which to compare districts or make important funding decisions.

(c) Failure to account for discharge pressures. This method of calculation determines service load by differences in admission rates alone. It assumes that each admission has the same length and the same cost. This lacks face-validity. People who are homeless at the point of admission are likely to require longer admissions to allow for their appropriate placement on discharge; this increased cost is not a failure of health services, rather a reasonable use of facilities for this extremely deprived group in the 
TABLE I

Access to Health formula applied to Bloomsbury mental health services

\begin{tabular}{lcccc}
\hline Group & $\begin{array}{c}\text { November } \\
1990^{*}\end{array}$ & Annual rate & $\begin{array}{c}\text { Population } \\
\text { estimates }^{* *}\end{array}$ & $\begin{array}{c}\text { Admission } \\
\text { rate/1000 }\end{array}$ \\
\hline Homeless & 9 & 108 & 3,371 & 32.0 \\
Other & 31 & 372 & 127,000 & 2.9 \\
Weighting factor & & & 11.0 & \\
\hline
\end{tabular}

*Data taken from table 2, p 22 Scheuer et al, 1991.

* Data taken from table 4, p 25 Scheuer et al, 1991.

(NFA figure of 320 taken from text, $p$ 24).

TABLE II

Access to Health formula: sub-groups of homeless people in mental health services

\begin{tabular}{lccccc}
\hline Group & $\begin{array}{c}\text { November } \\
1990^{*}\end{array}$ & $\begin{array}{c}\text { Annual rate } \\
\text { equivalent }\end{array}$ & $\begin{array}{c}\text { Population } \\
\text { estimates** }\end{array}$ & $\begin{array}{l}\text { Admission } \\
\text { rate/1000 }\end{array}$ & $\begin{array}{c}\text { Weighting } \\
\text { (homeless/other) }\end{array}$ \\
\hline B\&B/PSL & - & - & 2,011 & - & - \\
Hostel & 2 & 24 & 1,040 & 23 & 7.9 \\
NFA & 7 & 84 & 320 & 263 & 90.7 \\
Other & 31 & 372 & 127,000 & 2.9 & \\
\hline
\end{tabular}

* Data taken from table 2, p 22 Scheuer et al, 1991.

**Data taken from table 4, p 25 Scheuer et al, 1991.

(NFA figure of 320 taken from text, $p 24$ ).

absence of alternative social and community care. The health formula should therefore include discharge as well as admission pressures and be sensitive to change as social provision increases.

\section{Bloomsbury mental health services}

Evidence of some of these pressures has been accumulating in our mental health services and these will be used to illustrate both the general arguments about weighted capitation for homeless people and the specific issues relating to mental health needs of homeless people.

In order to allow comparability, data presented here refer to the old Bloomsbury Health Authority Services as defined in 1990 (before the formation of Bloomsbury \& Islington). Estimates of numbers of resident and homeless populations for Bloomsbury have been taken from the Kings Fund paper (Scheuer et al, 1991) on which most of the Access to Health calculations are based.

\section{Estimated annual unplanned psychiatric admission rates (Kings Fund data)}

Scheuer et al (1991) determined that in November 1990 , services of the old Bloomsbury Health Authority admitted seven people classed as "NFA" (no fixed abode), two from hostel addresses, none from B\&B and 31 others to acute psychiatric services (Table I). This yields a psychiatric capitation weighting, calculated by ratio of admission rates, of 32:2.9, i.e. $11: 1$. This is equivalent to applying the Access to Health method solely to mental health services, pooling categories of homelessness in view of the smaller numbers. It is therefore a baseline against which other approaches can be compared with reference to the Access to Health formula.

It is possible to calculate relative weightings for the different classes of homelessness (Stern, 1992; Access to Health, 1992) identified in this survey although these are likely to be somewhat inaccurate because of the low numbers and the tendency for homeless people to move from one kind of accommodation to another (Table II).

\section{Applying prevalence estimates for schizophrenia to homeless and resident groups}

This methodology produces the conclusion that 3,371 homeless people have the same number of unplanned psychiatric admissions as $(3,371 \times 11)$, i.e. about 37,000 , local residents. Similarly 320 people classified as NFA are equivalent to $(320 \times 90.7)$, i.e. about 29,000 , local residents; those living in hostels are equivalent to the balance, i.e. just over 8,000 local 
TABLE III

Weighted capitation (based on admissions) without assumptions in homeless numbers

Homeless admissions (HA)
Locally resident admissions (RA)
Total local residents (TLR)
Equivalent homeless

Homeless admissions (HA)

Total local residents (TLR)

Equivalent homeless

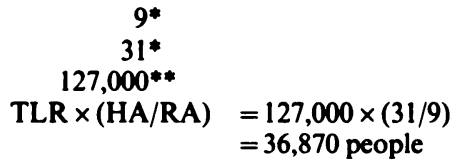

9*

$31^{*}$

$127,000^{* *}$

$\operatorname{TLR} \times(\mathrm{HA} / \mathrm{RA})=127,000 \times(31 / 9)$

$=36,870$ people

*Data taken from table 2, p 22 Scheuer et al, 1991.

**Data taken from table 4, p 25 Scheuer et al, 1991.

(NFA figure of 320 taken from text, $p$ 24).

residents. With this sort of weighting, it becomes apparent that even small fluctuations in numbers of roofless people in an area stand to have very marked effects on service demand. This potential for variation in demand must affect service planning in districts subject to these pressures. Yet even this figure is likely to be an underestimate. That there is a high prevalence of mental illness among the homeless is well established. Schizophrenia, for example, is characterised by so-called negative symptoms, such as isolation, lack of drive, apathy, as well as the tendency to hear voices or hold abnormal beliefs. It is likely to be a combination of these problems which renders its victims liable to become homeless. In surveys, about a third of homeless people have evidence of schizophrenia (e.g. Timms \& Fry, 1989; James, 1991). Given that this is the most frequent psychiatric hospital admission diagnosis, its impact on service is very significant indeed.

\section{Alternative approaches to developing a weighting}

Two approaches will be presented. The first attempts to deal with the inaccuracies in the estimates of number of homeless people. The second proceeds to take further account of the discharge pressures.

\section{Deficiencies in estimating numbers}

The limitations of the survey method have already been identified. A recent study has applied a new method of measuring homelessness in part of Bloomsbury (Fisher $e t$ al, in preparation). Significantly more homeless people were identified in one sector (NE Westminster) of Bloomsbury than Scheuer et al (1991) estimated were to be found in the whole district.

An alternative formula (Table III) allows each district to produce direct calculations based on demand as determined by its own figures for admission rates, rather than rely on weightings derived elsewhere and an estimated homeless number. On the face of it, it is a less desirable principle than the use of a population count and weighting; these at least give the appearance of a statement of community need. Yet if the quality of data is as weak as are these estimates of homelessness, and if the general weighting formula rests only on admission rates (a measure of demand) it is probably better to be straightforward about the deficiencies and promote a more robust approach at least initially.

\section{Applying data from a point survey of occupancy of services by homeless people}

A weighting based on need rather than demand would be ideal. In the absence of this, it still seems preferable to take account of admission and discharge demands. In March 1990, a single researcher visited all the acute psychiatry wards in Bloomsbury and interviewed anyone whose address was in doubt. This survey produced numbers for homeless and local residents in mental health beds (Fisher et al, 1990). There were 33 people with no permanent UK address, of which three were foreign residents and are discounted in this calculation (Table IV).

The advantage of a point survey of occupancy of acute psychiatric services is that it takes account of both admission and discharge pressures and therefore provides a fair representation of demand on the total in-patient service. Differential delays in discharge rates will lead to a relative accumulation of homeless people in services. The ratio of homeless to members of the resident population gives a valid indication of hospital costs for each of these groups. If anything, it probably marginally underestimates the costs of the homeless provision, because it does not include the additional services (e.g. outreach teams) specifically designed for this group.

By using a formula such as this which includes discharge as well as admission pressures, the weighting rises from 11 (Table I, calculated according to Access to Health criteria) to 21! Further work is required to determine if this means that homeless people tend to stay in hospital roughly twice as long or if this survey (using personal visits to wards) 
TABLE IV

A point survey of homeless people in Bloomsbury mental health services

\begin{tabular}{lccc}
\hline Group & $\begin{array}{c}\text { March 1990 } \\
\text { point survey* }\end{array}$ & $\begin{array}{c}\text { Estimated } \\
\text { population** }\end{array}$ & $\begin{array}{c}\text { In-patients/ } \\
\text { population( 1000) }\end{array}$ \\
\hline $\begin{array}{l}\text { Homeless } \\
\text { (excludes foreign residents) }\end{array}$ & 30 & 3,371 & 8.9 \\
$\begin{array}{l}\text { Permanent UK address } \\
\text { Weighting factor }\end{array}$ & 54 & 127,000 & 0.4 \\
\hline
\end{tabular}

*Data taken from Fisher et al, 1990.

**Data taken from table 4, p 25 Scheuer et al, 1991.

(NFA figure of 320 taken from text, $p$ 24).

TABLE V

Weighted capitation (based on occupancy) without assumptions about homeless numbers

\begin{tabular}{ll}
\hline Homeless patients (HP) & $30^{*}$ \\
Locally resident patients (RP) & $54^{*}$ \\
Total local residents (TLR) & $127,000^{* *}$ \\
Equivalent homeless & TLR $\times(\mathrm{HP} / \mathrm{RP})$ \\
& $=127,000 \times(30 / 54)$ \\
& $=70,556$ people \\
\hline
\end{tabular}

*Data taken from Fisher et al, 1990.

* Data taken from table 4, p 25 Scheuer et al, 1991.

(NFA figure of 320 taken from text, $p$ 24).

identified more homeless people. Two subsequent surveys (Pilling \& Fox, personal communication) have confirmed that about a third of acute psychiatric hospital beds covering this catchment area are occupied by homeless people so the broad conclusion must stand. It therefore appears that the capitation weightings proposed by Stern are certainly conservative and may be very significant under-representations of the actual pressures. Using this weighting, the 3,371 homeless people in Bloomsbury occupy as many acute psychiatric beds as $(3,371 \times \sim 21)$, i.e. 70,556 local residents. Moreover by examining occupancy rates in individual services a simple calculation, involving relative use of services by homeless and locally resident groups, can be made which does not, in fact, rely on the estimated number of homeless, one of the weakest elements of the calculation with present information methods (Table V).

\section{Conclusions}

There can be no doubt that capitation formulae need to be moderated to take account of health needs. The debate must concern the most appropriate and fair way of achieving this result. In mental health, this is likely to involve a social deprivation factor for the resident population and a weighting for homelessness.

A method of calculating a weighting for homeless people has recently been proposed. This was based entirely on estimated numbers of homeless people and relative admission rates. It has serious limitations with regard to both its assumptions. First, the numbers of homeless people are almost inevitably underestimates. Second, the weightings fail to take account of the real service pressures which certainly include issues to do with discharge into appropriate accommodation.

A new formula is described which might provide a better approach. It has three elements. Based on resident populations and the proportion of homeless to resident patients, it provides a simple way of assessing equivalent load on service. It is possible to use local admission figures (Table III) and achieve an equivalent population base without assumptions about number of homeless people. However, it is argued that better than this is to use a formula based on occupancy (Table $V$ ) which takes account of real service pressures. It may also provide an incentive to divert some of this resource subsequently into improving social care. Failure to calculate the true cost will inevitably lead to a poorer service for local residents as well as the homeless.

The patient information was here obtained by a simple point survey and the small numbers involved are a significant limitation. However, increasingly information systems are improving under the market pressures of contracting. These data could be used to calculate a weighting to be applied to estimated homeless numbers, but until better ways of counting homeless people exist, this approach is likely to be limited. Moreover, relatively small flows of people stand to have disproportionate effects on service demand; a method is required which can be reviewed more frequently than surveys would permit. This approach does not depend on estimated homeless populations. 
The development of increased hostel provisions in districts is to be encouraged. Yet the consequences of these on local health and social services must be acknowledged. For example, in Bloomsbury (South Camden sector), a new 150 bed hostel has recently been opened and a small nine-bed hostel for people discharged from special hospitals is also planned. Both projects will involve provision for people likely to need access to comprehensive psychiatric services at a rate greatly in excess of other local people.

The scale of the adjustment for mental health services is very large but this is compatible with the expected drift of people with schizophrenia into the anonymous hearts of our great cities. The additional pressures on social services are likely to be similar but need recognition separately through the community care funding.

It is of particular interest to compare these calculations with the results of the model outlined by Jarman et al (1992). In 1986, the expected number of admissions after adjusting for sex, age and martial status for Bloomsbury was 656. The predicted number using the Jarman model was 915 which compares well with the actual number of 1035 admissions. Using the model proposed here, however, the uplift for the homeless establishes a predicted total number of 1020 admissions, remarkably close to the actual figure. This rests on the assumption that the proportion of homeless people remained unchanged between 1986 and 1990 but it does provide some validation of the approach. It appears that through a number of routes, models can be constructed which adequately take account of genuine social pressures of homelessness and isolation (the largest individual factor identified by Jarman $e t$ al, 1992). This methodology calls out for widespread application to planning of service and, more importantly, to the appropriate allocation of funds.

Homeless people with schizophrenia admitted to hospital are, in general, not failures of a reprovision exercise following the closure of long-stay mental hospitals (Leff, 1993). However, they probably do represent, in part, a failure to provide a sufficient level of community alternatives for new patients who can no longer access the long-stay hospital services and for whom the pool of acute psychiatric beds is ever reducing.

The points raised in this article focus on mental illness and homelessness but resourcing the other health needs of homeless people are also likely to be affected by the same issues. Homeless people, as much as local residents, should be able to access the whole range of psychiatric services. Special projects involving outreach teams and hostel places will undoubtedly help to improve the quality of life for many people but they are insufficient to meet all needs. Service providers should be encouraged, not penalised, when they provide this comprehensive level of care. To achieve this, providers and purchasers share a common aim to ensure that weighted capitation is fair, accurate and sensitive to change.

The approach outlined here merely provides a more accurate way of acknowledging the cost of the current condition; a more ambitious article might have questioned the ability of homeless people to access current services and the potential for further developments.

\section{Acknowledgements}

We wish to acknowledge the generous support of Camden \& Islington Community Services NHS Trust in this project. We would also like to express our gratitude to Professor Steven Hirsch for his helpful comments on an earlier draft of this paper.

\section{References}

Access to Health (1992) Developing a Weighting for Homeless People. London: Access to Health.

Fisher, N. R., Turner, S W. \& PUgh R. (1990) Homeless and mentally ill. The Lancet, 335, 916-917.

JAMES, A. (1991) Homeless women in London: the hostel perspective. Health Trends, 23, 80-84.

Jarman, B., Hirsch, S., White P. \& Driscoll, R. (1992) Predicting psychiatric admissions. British Medical Journal 304, 1146-1151.

LEFF, J. (1993) All the homeless people - where do they all come from? British Medical Journal, 306, 669-670.

Royal College of Psychiatrists (1988) Psychiatric Beds and Resources: Factors influencing Bed Use and Service Planning. Report of a Working Party of the Section for Social and Community Psychiatry. London: Gaskell (Royal College of Psychiatrists).

Scheuer, M. A., Black, M., Victor, C., Benzeval, M. et al (1991) Homelessness and the Utilisation of Acute Hospital Services in London. London: Kings Fund Institute.

STERN, R. (1992) London weighting. Health Services Journal, (28 May 1992) 22-23.

Thornicroft, G., Margolius, O. \& Jones, D. (1992) The TAPS project 6: New long stay psychiatric patients and social deprivation. British Journal of Psychiatry, 161, 621- 624.

Timms, P. W. \& FRY, A. H. (1989) Homelessness and mental illness. Health Trends, 21, 70-71.

Tomlinson, B. (1992) Report on the Inquiry into London's Health Service, Medical Education and Research. London: HMSO. 